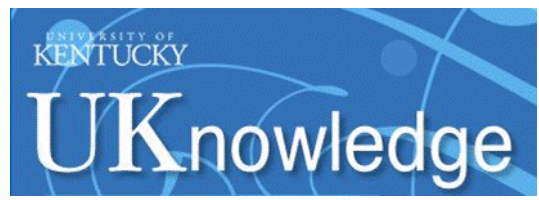

University of Kentucky

UKnowledge

Power and Energy Institute of Kentucky Faculty Publications

Power and Energy Institute of Kentucky

$6-2020$

\title{
A Network Graph Technique for the Design of Electric Aircraft Power Systems
}

\author{
Damien Lawhorn \\ University of Kentucky, damien.lawhorn@uky.edu \\ Vandana Rallabandi \\ GE Research, vandana.rallabandi@uky.edu
}

Dan M. Ionel

University of Kentucky, dan.ionel@uky.edu

Follow this and additional works at: https://uknowledge.uky.edu/peik_facpub

Part of the Power and Energy Commons

Right click to open a feedback form in a new tab to let us know how this document benefits you.

\section{Repository Citation}

Lawhorn, Damien; Rallabandi, Vandana; and Ionel, Dan M., "A Network Graph Technique for the Design of Electric Aircraft Power Systems" (2020). Power and Energy Institute of Kentucky Faculty Publications. 3.

https://uknowledge.uky.edu/peik_facpub/3

This Conference Proceeding is brought to you for free and open access by the Power and Energy Institute of Kentucky at UKnowledge. It has been accepted for inclusion in Power and Energy Institute of Kentucky Faculty Publications by an authorized administrator of UKnowledge. For more information, please contact UKnowledge@lsv.uky.edu. 


\section{A Network Graph Technique for the Design of Electric Aircraft Power Systems}

\section{Notes/Citation Information}

Published in Proceedings, IEEE Transportation Electrification Conference and Expo (ITEC), 2020.

(C) 2020 IEEE Copyright Notice. "Personal use of this material is permitted. Permission from IEEE must be obtained for all other uses, in any current or future media,including reprinting/republishing this material for advertising or promotional purposes, creating new collective works, for resale or redistribution to servers or lists, or reuse of any copyrighted component of this work in other works."

The document available for download is the authors' manuscript version that is accepted for publication. The final published version is copyrighted by IEEE and will be available as: D. Lawhorn, V. Rallabandi, D. M. Ionel, "ANetwork Graph Technique for the Design of Electric Aircraft Power Systems," Proceedings, IEEE Transportation Electrification Conference and Expo (ITEC), Chicago, IL, 5p., June 2020. 


\title{
A Network Graph Technique for the Design of Electric Aircraft Power Systems
}

\author{
Damien Lawhorn*, Graduate Student Member, IEEE, Vandana Rallabandi ${ }^{\dagger}$, Senior Member, IEEE, and \\ Dan M. Ionel*, Fellow, IEEE \\ ${ }^{*}$ SPARK Lab, Department of Electrical and Computer Engineering, University of Kentucky, Lexington, KY, USA \\ damien.lawhorn@uky.edu,dan.ionel@uky.edu \\ † GE Research, Niskayuna, NY, USA, vandana.rallabandi@ieee.org
}

\begin{abstract}
Today the electrification of flight is more popular than ever, creating a wide array of concept aircraft and associated power system topologies. In order to gain insights into benefits of these varying architectures, this paper introduces the development of a framework for electric aircraft power system (EAPS) optimization. The proposed framework accepts inputs from a designer in the form of component parameters and desired flight mission characteristics. A collective graph representing many architectures is formed, from which, subgraphs or power system topologies meeting the flight requirements are extracted and analyzed. An optimum topology meeting the flight requirements with minimum mass, maximum efficiency and reliability can be subsequently selected from these subgraphs. The presented results include the comparative analysis of different EAPS types with respect to the competing performance metrics of mass and efficiency.
\end{abstract}

Index Terms - graph theory, electric aircraft, power systems, optimization

\section{INTRODUCTION}

Electric aircraft are becoming increasingly more popular, driven by incentives such as fuel efficiency, cost, and noise pollution. Manufacturers have already begun electrification of many auxiliary systems in today's planes, as well as the demonstration of electrically propelled aircraft. These studies have produced a large number of designs, all of which vary greatly with respect to the power system (Fig. 1). Collaborative efforts with NASA have led to beginning the development of a tool which can be used to determine the optimal number of components and configuration within the power system. At the preliminary design stage, an aircraft's mission typically is determined, based on defined flight goals such as endurance and intended payload. Traditionally, the aircraft general topology of turbo-electric, hybrid-electric, or all-electric may be set based on its mission, primarily due to energy storage constraints. The leading electrical energy storage technology in electric vehicles, Lithium-ion, possesses a specific energy in the range of $230 \mathrm{Wh} / \mathrm{kg}$ [1]. Fossil fuel, with an energy density two orders of magnitude higher, holds an advantage over electric energy storage. Thus, when considering electrical energy storage for a commercial airliner such as the Boeing 777 , it may be expected that significantly more mass is required to achieve the same energy content as fossil fuel, and this severely limits the maximum flight time.

However, there are still many choices for a designer to make concerning the layout of a power system, including the degree

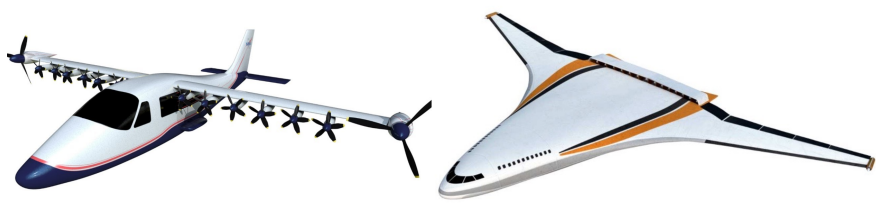

Figure 1. Example distributed electric propulsion aircraft designs by NASA with varying power system topologies. All-electric demonstrator X-57 Maxwell currently under development utilizing multiple electrical machines with varying ratings [2] (left). Conceptual turbo-electric N3-X aircraft which utilizing electrical energy from generators coupled to jet engines [3] (right).

of electrification, the number of components, distribution bus type, and voltage ratings [4].

This work proposes an approach, intended to be used as an early stage design tool, which utilizes mathematical methods such as graph theory to identify optimal solutions with regard to the electric aircraft power system (EAPS) configuration. This paper includes a case study for a sub-MW scale aircraft intended for a long-haul flight mission. Example results include performance trade-offs for an array of design candidates in the terms of efficiency and mass.

\section{Electric Aircraft Propulsion System REPRESENTATION}

An EAPS may be represented in the form of a graph network. The nodes of the graph are determined by the components incorporated in the power system architecture. For an electric aircraft, these may include but are not limited to electric machines, i.e. motors or generators, power converters, energy storage devices, and protection equipment (Fig. 2). Each component and its respective graphical node is assigned characteristics including but not limited to specific power or energy, operating efficiency, and failure rates. These characteristics may be constant values, such as a failure rate for a particular component, or they may vary with other variables related to that component. For example, efficiency may be calculated as a function of the components power rating and anticipated loading over the specified mission.

For the work done in this paper, a survey of many commercial and academic electric motors and jet engines was conducted (Fig. 3, Fig. 4). Based on a trendline fit to the survey results, the jet engine components were assigned a 


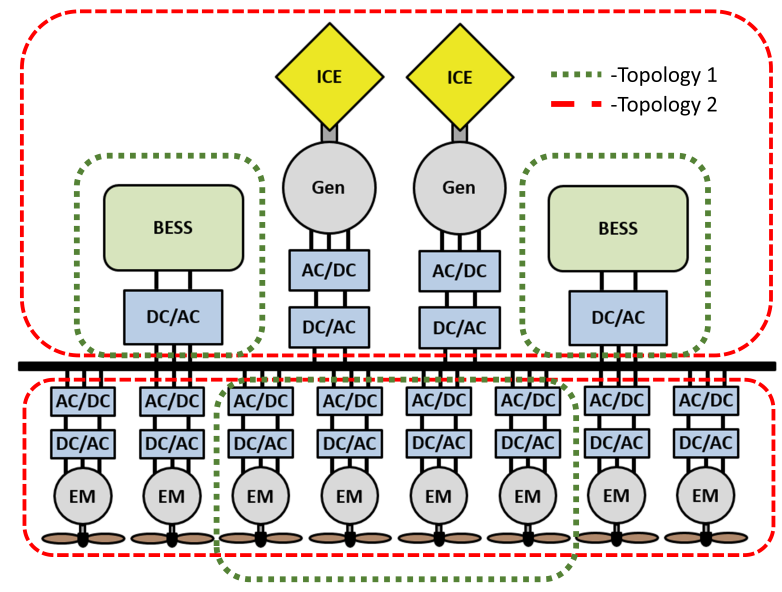

Figure 2. Different aircraft power system representations with a variable number and ratings of internal combustion engines (ICE), generators (Gen) rectifiers (AC/DC), battery energy storage systems (BESS), electric motors (EM), and inverters (DC/AC) are analyzed using a graph theory based approach.
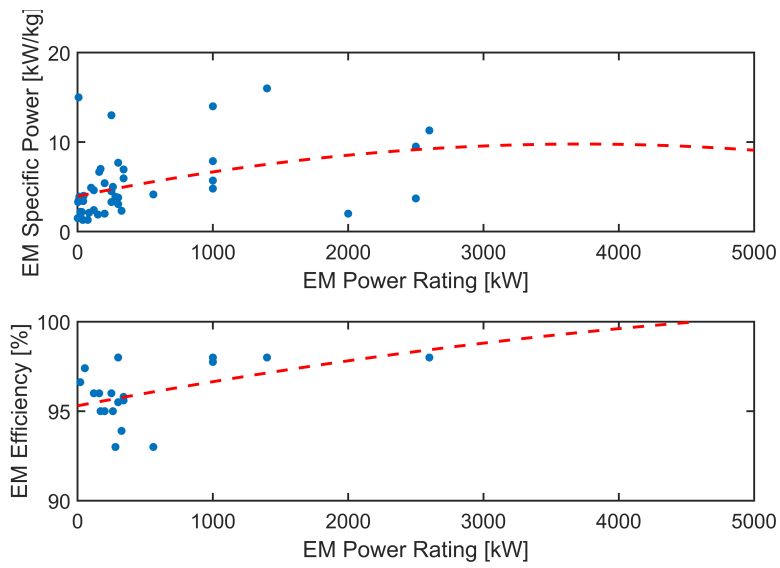

Figure 3. Collection of specific power and efficiency values for both academic and commercial electric machines designs based on a large set of references [5]-[18]. A trendline is extracted and used in the EAPS model.
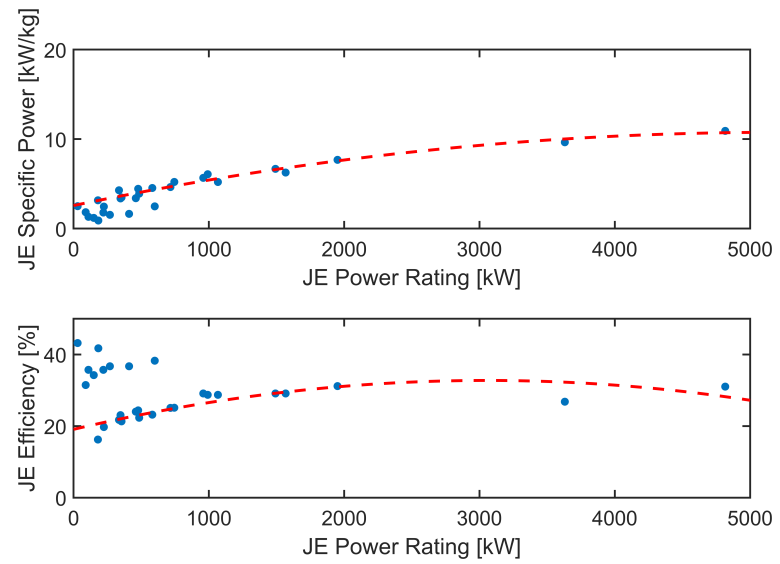

Figure 4. Survey of specific power and efficiency values for commercial jet engines, including both turbine and internal combustion engines based on a large set of references [19]-[25]. Trendlines shown are used in the EAPS model. specific power of $y=-4.789 e-07 x^{2}+0.004 x+1.534$, where power rating is the independent variable. Efficiency trends vary widely in reciprocal versus turbine engines, therefore a constant value of 29 percent was used. In the electric motor survey, trends show increasing specific power and efficiency as power rating increases, but a fitted trendline results in a poor $R^{2}$ value. Therefore, for electric motors it is assumed that specific power increases linearly from 4 to $10 \mathrm{~kW} / \mathrm{kg}$ and efficiency increases from 93 to 98 percent over the power range. It is assumed that power converters, and lithium-ion batteries have specific powers of 20 and $0.35 \mathrm{kw} / \mathrm{kg}$ respectively. Additionally for the same components, efficiencies are assumed as 98 and 95 percent. Energy storage is also considered in both Jet A fuel and Lithium-ion batteries where specific energy values of 12.08 and $0.25 \mathrm{kWh} / \mathrm{kg}$, respectively, are assumed.

The edges of a graph represent interconnections between the various components. A graph for an EAPS is directed to signify possible directions of power flow. Some nodes such as an auxiliary heating unit may only accept power, therefore its edges should only be directed toward and not from the node. These edges may be assigned weights, examples include mass associated with the inclusion of a particular vertex, power flow capacity, or physical distance. Further descriptions of how power systems may be represented as graphs can be seen in [26], [27]. Connectivity in between the various graph vertices may be used for minimal path calculation as in this study to determine lowest mass or highest efficiency. Additional studies in the literature have used graph theory for reliability evaluation by utilizing minimum cut sets to determine power loss scenarios [28].

\section{Optimization PROCESS}

The optimization process begins with inputs from the system designer regarding the intended use of the aircraft and technology available. Vehicle goals such as desired fuel savings, power requirement at maximum lift, and flight profiles may be initially introduced by the user and later used as constraints. In addition to these vehicle-level inputs, the user also must define component-level information for the framework to use. These attributes include specific power and energy, efficiency, and failure rates. These may be defined static values as described earlier, or by ranges depending on the availability of resources to the aircraft designer.

Introduction of ranges for component attributes also enables the use of sensitivity analysis to determine which components and attributes have the largest influence on performance metrics. In this study, a survey of various aircraft components was conducted to obtain values for efficiency and specific power as a function of power (Fig. 3 \& Fig. 4). To further the accuracy of the power system model, additional components such as gearboxes may be modeled, as seen in [29].

Once the components under consideration and the desired ranges are defined, a graph is constructed to represent many candidate designs (Fig. 5). An iterative process is established for the addition of commonly seen power flow paths into 


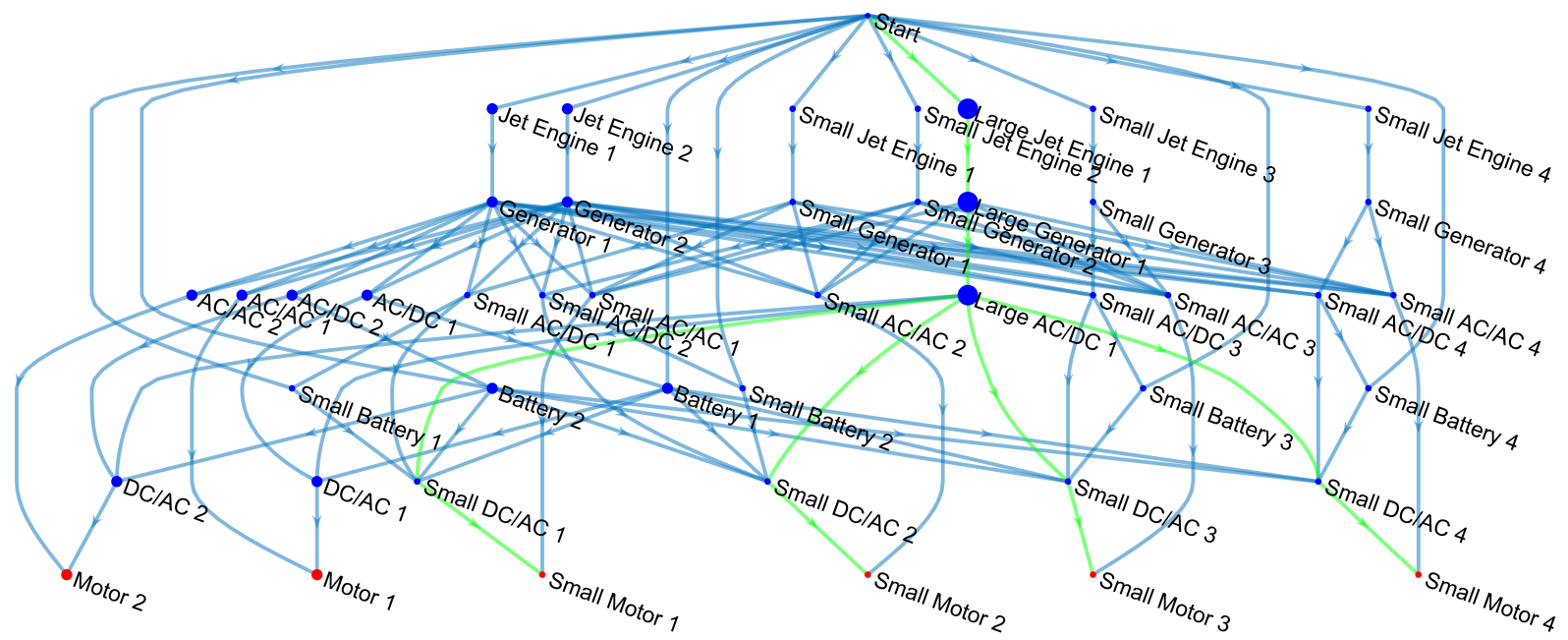

Figure 5. Graph containing power system components seen in hybrid and turbo-electric aircraft topologies with varying ratings. The illustrated graph represents thousands of potential candidate designs. The developed framework extracts valid subgraphs meeting the flight requirements for further analysis.

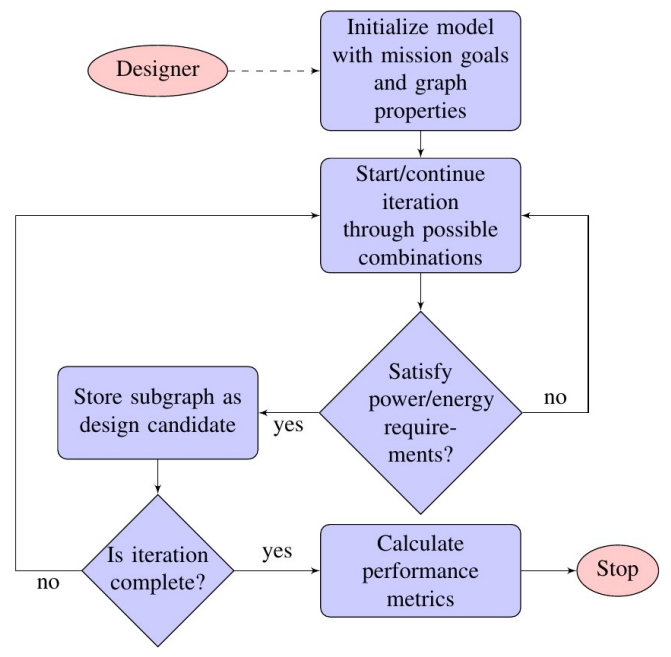

Figure 6. Workflow for the EAPS optimization process. The designer begins the approach by defining system characteristics and the framework outputs how viable power systems perform based on specified metrics. Example performance metrics include mass and efficiency.

the graph to avoid excessive manual entries by the user One example of a common path starts from a jet engine as a generation source, which converts mechanical energy to electrical through an $\mathrm{AC}$ generator, from this point the power can be rectified with a $\mathrm{AC} / \mathrm{DC}$ converter, then this power can be used to drive an $\mathrm{AC}$ motor through a DC/AC inverter.

From the full graph, thousands of architectures are extracted which meet the power and energy requirements input by the user. In order to consider all topologies that fulfill the mission, every possible combination of propulsor and energy source is considered. Subgraphs are then created with paths that satisfy the constraints on the system:

$$
P_{\text {flight }}=\sum_{i=1}^{n} P_{\text {propulsor }_{i}}, \quad E_{\text {flight }}=\sum_{i=1}^{n} E_{\text {cap } i},
$$

where $P_{\text {flight }}$ is the maximum power required for the aircraft, and $E_{\text {flight }}$ is the total energy required for a specific flight profile. Subgraphs are created using the previously defined energy sources and motor loads combinations with minimum path algorithms to define power conversion components in a path. This extraction process is illustrated in Fig. 6.

With a collection of valid subgraphs, post-processing may be done to evaluate the performance characteristics of the graph (Fig 7). The total system mass can be easily calculated as the sum of the masses of all individual components. Nodes that represent power conversion devices or loads derive their mass from the node's rating and the associated specific power. The mass for those nodes which represent energy sources, such as the jet engine fuel and batteries, is calculated using specific energy. A special case is introduced for the jet engine nodes, which represent both engine and fuel storage. The total node mass is calculated as the sum of engine mass, based on specific power, and the required fuel mass, based on specific energy and specific fuel consumption.

Another performance metric which may be of interest to a designer is the overall system efficiency. The efficiency of an EAPS not only affects fuel consumption, but also must be considered for thermal management system sizing. Any additional equipment required to dissipate excess waste heat adds to the total system mass, which is undesirable. The overall system efficiency may be calculated as

$$
\eta_{\text {system }}=\frac{\left.E\left(\eta_{\text {comb }}(1-\zeta)\right)+\left(\eta_{\text {elec }} \zeta\right)\right)}{E},
$$

where $\eta_{c o m b}$ represents the efficiency of a path from the 


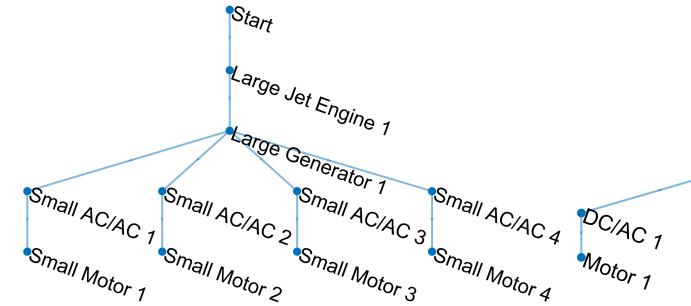

(a)

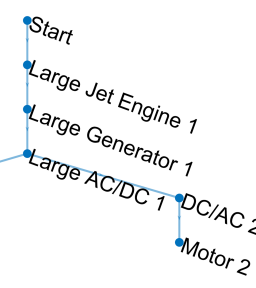

(b)

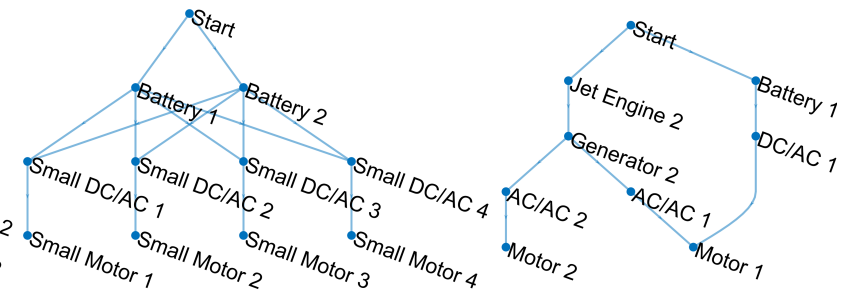

(c)

(d)

Figure 7. A collection of potential design candidates to fulfill an electric aircraft concept which meets the flight power and energy requirements predetermined by the system designer. All the shown topologies were selected automatically as subgraphs from the graph shown in Fig. 5 . These architectures include purely turbo-electric, hybrid-electric and all-electric energy storage means. Subgraphs are arranged in order of ascending mass from 600 to $3000 \mathrm{~kg}$.

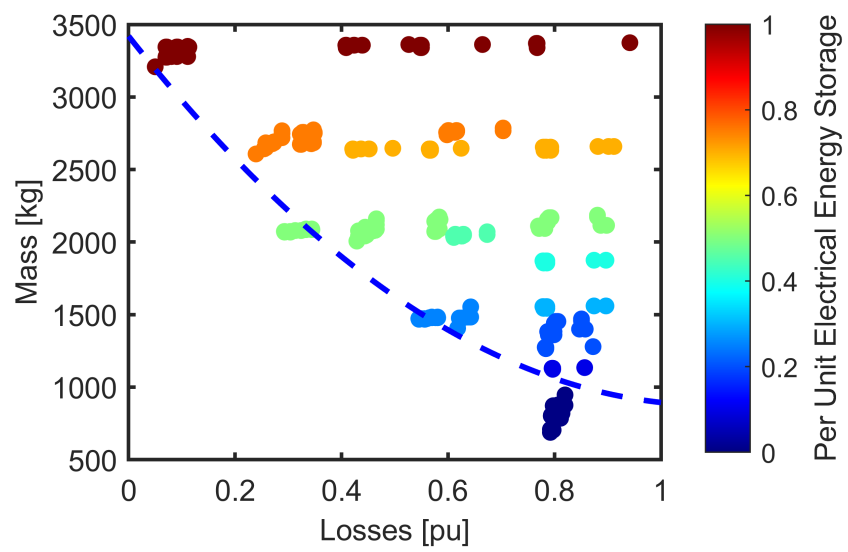

Figure 8. Comparison of overall system loss and the total electrical system mass for varying degrees of electrification. Designs with purely electrical energy storage have higher efficiencies at the penalty of more mass, while purely turbo-electric designs are least massive and least efficient.

combustion engine source to a motor load, $\eta_{\text {elec }}$ represents the efficiency of a path stemming from battery energy storage, and $\zeta$ is the per unit electrical energy storage, being a value from zero to one. For a fully turbo-electric architecture, $\zeta$ will be equal to zero, as all the energy used for flight is stored in the jet fuel. It is assumed that the battery is charged pre-flight independently of the engine.

This framework is currently under development and example studies are conducted for a $500 \mathrm{~kW}$ peak power electric aircraft. The total system efficiency versus EAPS mass for multiple values of $\zeta$ is shown in Fig. 8. The results from Fig. 8 indicate that higher efficiency is achieved at the cost of mass in systems with battery energy storage, which is in line with expectations, and therefore confirms the applicability of the proposed approach.

\section{CONCLUSION}

Electric aircraft designs today show large variations in power system types as well as number of components used. This paper presents developments toward an optimization approach for aircraft power systems which incorporate electric propulsion. The proposed approach is capable of evaluating thousands of design candidates based on performance metrics such as mass and efficiency. This paper includes a study for an aircraft designed for a long-haul mission, such as those seen in commercial aviation. The case study power system candidate pool includes both conventional jet and electrical propulsion systems, with design candidates in varying degrees of electrical energy storage. This framework has been used to perform a comparative evaluation of potential power system architectures with respect to mass and efficiency. Results show that architectures incorporating greater per unit electrical storage may be more efficient, at the penalty of more mass. Additionally, in architectures which have the same degree of electrical energy storage, those with larger rated components exhibit less total mass.

\section{ACKNOWLEDGMENT}

The research described in this paper is based upon work supported by NASA Kentucky under NASA award No: KY GF-19-051.

\section{REFERENCES}

[1] M. A. Hannan, M. M. Hoque, A. Hussain, Y. Yusof, and P. J. Ker, "State-of-the-art and energy management system of lithium-ion batteries in electric vehicle applications: Issues and recommendations," IEEE Access, vol. 6, pp. 19362-19378, 2018.

[2] S. Clarke, M. Redifer, K. Papathakis, A. Samuel, and T. Foster, "X57 power and command system design," in 2017 IEEE Transportation Electrification Conference and Expo (ITEC), June 2017, pp. 393-400.

[3] J. Felder, "Nasa n3-x with turboelectric distributed propulsion," NASA Glenn Research Center, Tech. Rep., November 2014. [Online]. Available: https://ntrs.nasa.gov/search.jsp?R=20150002081

[4] C. E. Jones, P. J. Norman, S. J. Galloway, M. J. Armstrong, and A. M. Bollman, "Comparison of candidate architectures for future distributed propulsion aircraft," IEEE Transactions on Applied Superconductivity, vol. 26, no. 6, pp. 1-9, Sep. 2016.

[5] "Electric motor demonstrator sets two world records in two hours after five years of work," Nov 2019. [Online]. Available: https://car.osu.edu/news/2019/11/ electric-motor-demonstrator-sets-two-world-records-two-hours-after

[6] A. K. Yoon, D. Lohan, F. Arastu, J. Xiao, and K. Haran, "Direct drive electric motor for starc-abl tail-cone propulsor," AIAA Propulsion and Energy 2019 Forum, 2019.

[7] "Electric propulsion components with high power densities for aviation," 2015. [Online]. Available: https://nari.arc.nasa.gov/sites/ default/files/attachments/Korbinian-TVFW-Aug2015.pdf

[8] R. W. Dyson, R. H. Jansen, K. P. Duffy, and P. J. Passe, "High efficiency megawatt machine rotating cryocooler conceptual design," in 2019 AIAA/IEEE Electric Aircraft Technologies Symposium (EATS), 2019, pp. 1-15.

[9] "Yasa 750r," 2018. [Online]. Available: https://www.yasa.com/yasa-750/ 
[10] "Yasa p400r," 2018. [Online]. Available: https://www.yasa.com/ yasa-400/

[11] "1 megawatt power generator," 2019. [Online]. Available: https://aerospace.honeywell.com/content/dam/aero/en-us/documents/ learn/products/electric-power/brochures/N61-2229-000-000_ 1MW-Generator-br.pdf

[12] X. Zhang, C. L. Bowman, T. C. O'Connell, and K. S. Haran, "Large electric machines for aircraft electric propulsion," IET Electric Power Applications, vol. 12, no. 6, pp. 767-779, 2018.

[13] “E-motor," 2019. [Online]. Available: https://www.mclaren.com/applied/ products/item/e-motor-120kw-130nm/

[14] A. Yoon, Xuan Yi, J. Martin, Yuanshan Chen, and K. Haran, "A highspeed, high-frequency, air-core pm machine for aircraft application," in 2016 IEEE Power and Energy Conference at Illinois (PECI), 2016, pp. $1-4$.

[15] H. Lin, H. Guo, and H. Qian, "Design of high-performance permanent magnet synchronous motor for electric aircraft propulsion," in 201821 st International Conference on Electrical Machines and Systems (ICEMS), 2018, pp. 174-179.

[16] "Hvh410-150 electric motor," 2016. [Online]. Available: https: //cdn.borgwarner.com/docs/default-source/default-document-library/ remy-pds---hvh410-150-sheet-euro-pr-3-16.pdf?sfvrsn=a642cd3c_11

[17] Z. Zhang, W. Geng, Y. Liu, and C. Wang, "Feasibility of a new ironless-stator axial flux permanent magnet machine for aircraft electric propulsion application," CES Transactions on Electrical Machines and Systems, vol. 3, no. 1, pp. 30-38, 2019.

[18] "Emrax 348," 2020. [Online]. Available: https://emrax.com/e-motors/ emrax-348/

[19] "Compact, quiet, low-vibration, high-efficiency rotary engines," 2018.
[Online]. Available: https://liquidpiston.com/wp-content/uploads/2018/ 07/LiquidPiston-X-Specifications-2018-05-14-3.pdf

[20] "Zoche aero-diesels," 2000. [Online]. Available: http://www.zoche.de/ specs.html

[21] "Cd-200 jet-a enginer series," 2020. [Online]. Available: http://www.continentalmotors.aero/uploadedFiles/Content/ Engines/Diesel_Engines/CD200-SpecSheet.pdfl

[22] "Gemini diesel engines." [Online]. Available: https://www.geminidiesel.aero/application/files/5014/2828/3029/ GEMINI_GenInfoSht_LowRez.pdf

[23] "Helicopters." [Online]. Available: https://www.rolls-royce.com/ products-and-services/civil-aerospace/helicopters

[24] "Helicopter engines," 2019. [Online]. Available: https://www.pwc.ca/ en/products-and-services/products/helicopter-engines

[25] "Engines," 2020. [Online]. Available: https://aerospace.honeywell.com/ en/learn/products/engines

[26] D. Lawhorn, V. Rallabandi, and D. M. Ionel, "Scalable graph theory approach for electric aircraft power system optimization," in 2019 AIAA/IEEE Electric Aircraft Technologies Symposium (EATS), August 2019, pp. 1-5.

[27] T. A. Trapp, "Shipboard integrated engineering plant survivable network optimization," Ph.D. dissertation, Massachusettes Institute of Technology, 2015.

[28] Y. Zhao, Y. Che, T. Lin, C. Wang, J. Liu, J. Xu, and J. Zhou, "Minimal cut sets-based reliability evaluation of the more electric aircraft power system," Mathematical Problems in Engineering, vol. 2018, 2018.

[29] H.-J. Steiner, P. Vratny, C. Gologan, K. Wieczorek, A. Isikveren, and M. Hornung, "Optimum number of engines for transport aircraft employing electrically powered distributed propulsion," CEAS Aeronautical Journal, vol. 5, pp. 157-170, 062014. 